\title{
Towards Urban Densification: Parametric Modeling of Possible Scenarios for Urban Mobility
}

\section{SIGRADI2018 TECHNOPOLITICAS xxii congresso da sociedade iberoamericana de gráfica digital 22th conference of the iberoamerican society of digital graphics 07|08|09|novembro|2018 iau usp | são carlos | sp br}

\author{
Marcela Noronha Pinto de Oliveira e Sousa \\ University of Campinas | Brazil | m024502@dac.unicamp.br
}

Maria Gabriela Caffarena Celani

University of Campinas | Brazil | celani@fec.unicamp.br

\begin{abstract}
This article presents a literature review on the relationship between urban design and travel demand, and systematically maps existing studies in generative, parametric and procedural urban modeling that have approached the subject. The methods used in these papers are discussed, and the computational tools described in them are analyzed to identify how they can be used to support the design process for retrofitting urban streets. The findings are used to identify what further developments are needed in order to allow for visualizing the impact of design decisions on modal share.
\end{abstract}

Keywords: Urban design; Parametric urbanism; Travel behavior; Built environment.

\section{INTRODUCTION}

Regardless of new technologies and approaches already offering alternatives to traditional means of transportation, or that may arise in the future, the prevalence of the private car generates a fundamentally unsustainable urban model, as it encourages urban sprawl. Thus, urban mobility is one of the main factors for achieving sustainability and existing road infrastructure must be retrofitted to accommodate higher urban densities (Lehmann, 2016).

Densification allows the optimization of resources and can reduce the use of private cars by reducing individual daily travel. However, it produces a challenge for mobility, because the number of displacements per area is much higher in denser settings (Farr, 2013). According to Ewing, Tian \& Lyons (2018) the problem is that it "concentrates origins and destinations" (p.94), so even if distances traveled are shorter, travel speed is lower.

To solve these conflicts between mobility and sustainability many cities have turned to urban design and planning to restrain automobile dependency in cities (Ewing \& Cervero, 2010). The influences of the built environment on travel form a vast and well-studied field of research. However, the application of this research to inform urban planning and design presents difficulties, because of the difference between methods and variables used across studies. In 2010, Ewing and Cervero, took on the task of conducting a meta-analysis on "Travel and the Built Environment". In this study the authors surveyed researches studying how changes in the built environment could be used to reduce vehicle miles traveled and stimulate walkability and transit use in urban settings. The results of these studies were combined to arrive at effect sizes, expressed as elasticities, that could be used in tools for urban planning and design, such as sketchplanning implementations. The variables they analyzed were grouped under five D-variables: density, diversity, design, destination accessibility and distance to transit. To these five D-variables a sixth variable for Neighborhood type was added later. It is defined as the difference between travel generated in walkable neighborhoods in relation to that in regular suburban neighborhoods (Ewing
\& Cervero, 2010). This methodology enabled them to systematically combine data from their survey to calculate elasticities, which relate a $1 \%$ increase in any $D$-variables to the percentage change in Vehicle Miles Traveled (VMT). These elasticities can be used to inform planning decisions.

Stevens (2017) reproduced the study by Ewing and Cervero (2010) using recent data and found that individually D-variables can have little effect on travel behavior. However, these conclusions have been challenged by important names is the field. Handy (2017) believes that the elasticities calculated by Stevens (2017) are far from insignificant. Furthermore, she suggests that if the need to reduce car use is clear, even if "compact development cannot reduce driving very much on its own...we cannot reduce driving very much without it" (HANDY, 2017, p.28).

Ewing and Cervero (2017) believe the effect of Dvariables on travel behavior is "multiplicative" (p.20) and that their combined effect can be even greater than what can be measured through elasticities. Thus, cities must find ways to expand the access to public transit and promote active modes of transport, such as walking and cycling, so people can choose socially and environmentally responsible lifestyles (Carlow, 2016).

Even if design is only one of the D-variables, density and diversity have long been regarded as subjects of urban design and are generally believed to be directly related to the field, as exemplified by the seminal text by Jane Jacobs (1961), which has been called "the most robust piece of theory within the field of urban design" (Dovey \& Pafka, 2016). Therefore, what is considered design for the field of transportation is not necessarily the same as the concept of design for urban designers. Long-term results from the interaction between a series of factors, such as compact development, street and building design, mixed uses, and even residential self-selection, are more important to urban design than their separate contributions to travel behavior. 
For Gunder (2011) urban design should be a subject of urban planning concerned with "urban form, livability and aesthetics" (p.184). However, the topic of urban design and its role in the built environment has been the subject of many discussions (Foroughmand Araabi, 2017).

According to Cuthbert (2007) definitions of urban design have been an exercise in futility because of the fragmented perceptions of its function, methods and theoretical foundations. Thus, attempts at definitions are so general that they can be both irrefutable and meaningless at the same time. By mapping fifty years of attempts of definition he arrives at the idea that "the theoretical object of urban design is civil society" specifically "the public realm", therefore the "organic production of urban forms and spaces are homologous with the production of society" (p.179). The author suggests that urban design is akin to "to the production and reproduction of urban form" (p.185). Urban design, therefore, cannot be separated from social laws, culture, politics and the economy, but is in fact one of the pillars of civil society, both a product of it and an agent for its transformation. It can be used to influence social order, while at the same time being influenced by it (Cuthbert, 2007). From such a view, it could be concluded that the role of the urban designer is similar to that of a social engineer, that disrupts behaviors through the design of the built environment causing social reorganization, in order to steer the city towards a desired path of development. This can have both positive and negative outcomes depending on the governing forces behind urban design such as common wellbeing, economic gain, private and corporate interests.

Marshall (2012), despite discussions such as the previously mentioned on the difficulties to define urban design, describes it as "an art or technical practice involving the physical organization of buildings and spaces, towards a civic purpose" (p.258). Its practice finds support in scientific theories, often taken from other fields of knowledge, and seldom tested for their ability to represent the reality in the urban context. The author also states that urban design is largely based on untested, or even refuted theories, and is, thus, dangerously posed on the brink of becoming a pseudo-science.

In response to Marshall (2012), Dovey and Pafka (2016) state that urban design is a field that ranges from "the mathematics of urban morphologies and the sociology of public space to the interpretation of design quality and aesthetics" and is "a particular form of diagrammatic socio-spatial knowledge" (p.1). It uses "abductive" (p. 8) methods to develop plausible speculations for observed phenomena, not for a lack of scientific rigor, but because the city presents a type of problem that can be best explained as a complex adaptive system, which defies the formulation of rigid scientific theories. Hence, urban design is not a pseudo-science as Marshall (2012) suggests, but a "proto-science" (Dovey \& Pafka, 2016, P.8). They perceive a need for the characterization of "quantitative dimensions" (p.9) for urban design but suggest that the field cannot be defined by this single aspect. This concept resonates with Marshall's (2009) understanding of the city as an ecosystem that evolves from its internal interactions, and that urban planning should focus on local interventions, that allow the system to reorganize, and not on master plans that redesign cities to fit within preconceived ideals. Generative processes and selection of successful results can be used to guide the process of urban development. Therefore, urban design can be a greater force for change in the built environment than what is generally accounted for by the field of transportation.

The following section presents the methodology used to conduct this systematical mapping of literature $(\mathrm{SML})$ on parametric, generative and procedural computational tools that relate changes in the built environment to travel behavior. The most relevant papers in the sample and their resulting computational tools are reviewed. The findings are used to identify further developments needed to support the design process for retrofitting urban streets through the assessment of the impact of design decisions on modal share.

\section{METHODOLOGY}

A Systematical Mapping of Literature (SML) was conducted to review the state of the art in computational design tools that relate travel behavior and the built environment from the perspective of urban design. The understanding of tools, methods and models for the practice of urban planning and design is very wide and spans across theoretical, computational and pedagogical frameworks. Thus, this SML focused on the exploration of tools with parametric, generative or procedural approaches towards urban modeling using travel behavior data. Variations of these initial terms were surveyed in the papers from each field to try to cover common terms with similar meanings that could be of interest to this research. The strings were incrementally generated through successive tests in Google Scholar. New terms that proved interesting were added and terms that were too broad to generate relevant results were removed. Different spellings were tested for the words behavior and modeling because not every search engine supports stemming or wild card characters. The resulting strings were:

a. ("travel behavior" OR "travel demand" OR congestion OR traffic OR walkability) AND ("generative urban modeling" OR "generative urban model" OR "generative urban design" OR "generative urbanism")

b. ("travel behavior" OR "travel demand" OR congestion OR traffic OR walkability) AND ("parametric urban modeling" OR "parametric urban modelling" OR "parametric urban model" OR "parametric urban design" OR "parametric urbanism")

c. ("travel behavior" OR "travel demand" OR congestion OR traffic OR walkability) AND ("procedural urban modeling" OR "procedural urban modelling" OR "procedural urban model" OR "procedural urban design" OR "procedural urbanism")

The developed strings were used to conduct searches in various search engines: Web of Science, Science Direct, Scopus, Compendex, ProQuest, Sage Journals, Springer Link, Wiley Online, EBSCO and CumlnCAD. CumInCAD uses a different search engine that does not support the strings above, generating an excess of irrelevant results. Thus, a manual search had to be conducted using all terms individually to better control the relevance of the hits. Only papers that discussed generative, parametric or procedural approaches to urban planning and design were included in the final sample. Figure 1 shows how the distribution of articles across search engines. 


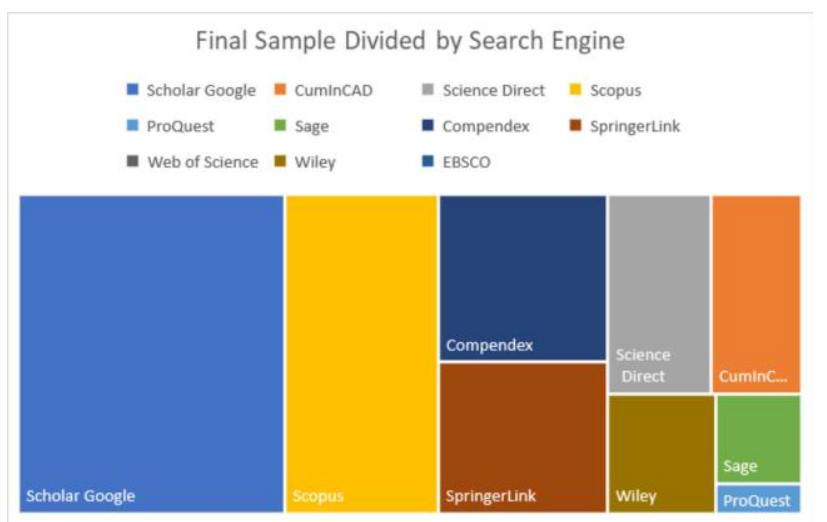

Figure 1: Volume of papers in the final sample found in each of the referred search engines. Source: Authors.

Furthermore, the papers had to present support methods or tools focused on travel behavior, approaches to congestion, traffic problems or improving walkability. Theses and dissertations were not used in the SML. However, authors and titles were searched in the snowballing phase to check if the research had generated articles or conference papers. This produced no further results because articles from relevant theses had already appeared in other searches, and some had produced no further publications. Finally, results from Google Scholar were surveyed to see if there were relevant results that had not appeared yet or to add other engines when necessary. Only peer-reviewed articles and conference papers were added to the sample.

A total of 98 papers were reviewed. Figure 2 shows the distribution of the papers according to their computational approach to urban modeling. Parametric modeling is referenced across all papers. Nevertheless, over half of the sample focuses on generative and procedural urban modeling.

Total Articles by Main Modeling Approach

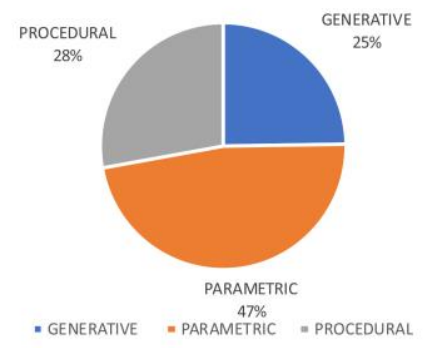

organizes the articles that are most relevant to this research by their main approach to urban modeling, tools they developed and software and scripting languages used for development. Only articles that present approaches for modeling travel behavior in relation to the built environment were used in the table. Nonetheless, the following review also uses articles to situate and further explain the relevant research. These were not included in the table for intelligibility.

Weber et al. (2009) developed a procedural urban modeling tool that simulates urban development over time, simulating procedural network development and
Figure 2: Articles in the final sample divided by the main modeling approach. Source: Authors.

Figure 3 shows the distribution of the papers according to the date and type of publication (journal articles or conference papers). The interest in the subject has remained constant in the past five years, with many contributions presented in conferences and journals. The papers in the final sample were surveyed to find approaches and tools relevant to the present research, and to present the state of the art in the subject.

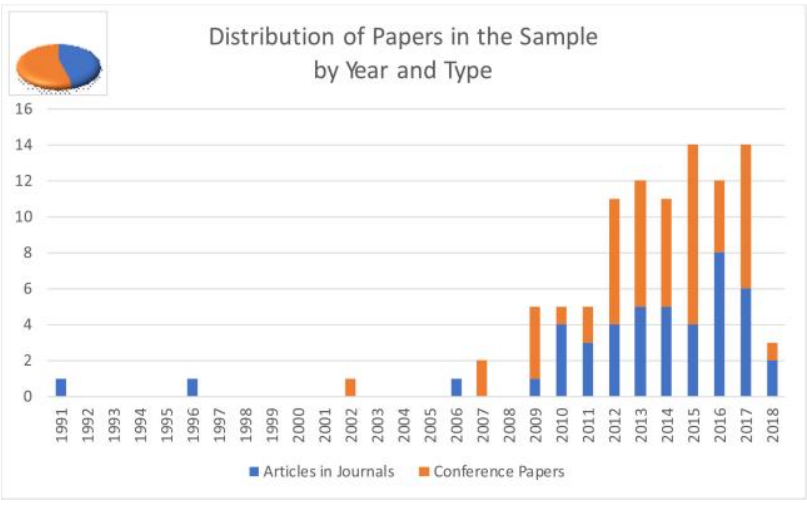

Figure 3: Distribution of papers by year of publication and type. Source: Authors.

\section{RESULTS}

Several articles from the sample described above were reviewed in the following section according to their relevance to the proposed research. Initially, procedural approaches are discussed as they form a set of related research conducted by dialoguing research groups with some coauthors collaborating across publications. Tools such as UrbanSim (urbansim.com/udst) and CityEngine (esri.com/software/cityengine) are discussed across these publications. Parametric and generative approaches are discussed further down. The same type of collaboration across research groups was identified, thus instead of following a chronological order for the survey, the approaches are grouped by related projects and tools. The related papers are from researchers working on the City Information Modelling (CIM) platform; UMI (urbanmodellinginterface.ning.com); UNA Toolbox (cityform.gsd.harvard.edu/projects/una-rhino-toolbox) and DeCodingSpaces Toolbox (decodingspaces.de). Generative and parametric approaches use mainly Rhino3D and Grasshopper (rhino3d.com), with custom components scripted in C\#, Python, VB-NET. changes to the built environment. Instead of using traditional traffic demand microsimulation methods, that only work on lager scales and in static settings, the authors chose a stochastic model. Their model distributes a given number of trips over the network through sampling. As the street systems grows, trips are simultaneously redistributed using a shortest path algorithm. The tool developed by the authors is useful for planners because it is a generic environment which allows users to simulate urban development at the street level; network and population growth, and changes in land use patterns, over large spans of time. 
Table 1: Most relevant articles divided by modeling approach, affiliation and characteristics of tool development

\begin{tabular}{|c|c|c|c|c|c|c|c|c|}
\hline $\begin{array}{l}\text { Main Modeling } \\
\text { Approach }\end{array}$ & Affiliation & Publication & Tool Development & Research Objective & Software & $\begin{array}{l}\text { Programming } \\
\text { Language// } \\
\text { Approach } \\
\end{array}$ & $\begin{array}{c}\text { Applies } \\
\text { Concepts of } \\
\text { Shape } \\
\text { Grammar } \\
\end{array}$ & $\begin{array}{c}\text { Applies } \\
\text { Concepts of } \\
\text { Pattern } \\
\text { Language } \\
\end{array}$ \\
\hline \multirow{5}{*}{ Procedural } & $\begin{array}{l}\text { ETH Zurich/ } \\
\text { Procedural Inc./ } \\
\text { Arizona State } \\
\text { University }\end{array}$ & $\begin{array}{l}\text { Weber, Müller, } \\
\text { Wonka \& Gross, } \\
2009\end{array}$ & $\begin{array}{l}\text { CityEngine Procedural } \\
\text { Inc. (later Esri } \\
\text { CityEngine) }\end{array}$ & $\begin{array}{c}\text { Simulation of } \\
\text { geometric aspects } \\
\text { of urban } \\
\text { development at the } \\
\text { street level. }\end{array}$ & CityEngine & & YES & NO \\
\hline & $\begin{array}{c}\text { ETH Zurich - } \\
\text { Computer Vision } \\
\text { Lab and } \\
\text { Information } \\
\text { Architecture/ } \\
\text { Procedural Inc. }\end{array}$ & $\begin{array}{l}\text { Aschwanden, } \\
\text { Haegler, Bosché, } \\
\text { Van Gool \& } \\
\text { Schmitt, } 2011\end{array}$ & & $\begin{array}{l}\text { Simulation of } \\
\text { occupant behavior } \\
\text { for procedural } \\
\text { modelling of cities. }\end{array}$ & $\begin{array}{l}\text { CityEngine and } \\
\text { Massive Software }\end{array}$ & $\begin{array}{l}\text { CGA-Computer } \\
\text { Generated } \\
\text { Architecture }\end{array}$ & YES & NO \\
\hline & $\begin{array}{c}\text { ETH Zurich - } \\
\text { Computer Vision } \\
\text { Lab and } \\
\text { Information } \\
\text { Architecture } \\
\end{array}$ & $\begin{array}{l}\text { Koltsova, Kunze \& } \\
\text { Schmitt, } 2012\end{array}$ & & $\begin{array}{l}\text { Development of a } \\
\text { support method for } \\
\text { designing urban } \\
\text { space at the human } \\
\text { scale. }\end{array}$ & $\begin{array}{l}\text { CityEngine and } \\
\text { Rhinoceros } 3 D\end{array}$ & $\begin{array}{l}\text { Visual } \\
\text { Programming - } \\
\text { Grasshopper }\end{array}$ & YES & YES \\
\hline & $\begin{array}{l}\text { Purdue } \\
\text { University }\end{array}$ & $\begin{array}{c}\text { Garcia-Dorado, } \\
\text { Aliaga \& Ukkusuri, } \\
2014\end{array}$ & $\begin{array}{l}\text { Extension for } \\
\text { UrbanSim// } \\
\text { UrbanCanvas }\end{array}$ & $\begin{array}{l}\text { Procedural design } \\
\text { tool for matching } \\
\text { road network with } \\
\text { travel behavior. }\end{array}$ & UrbanSim & & NO & NO \\
\hline & $\begin{array}{l}\text { ETH Zurich - } \\
\text { Institute for } \\
\text { Transport } \\
\text { Planning \& } \\
\text { Systems }\end{array}$ & $\begin{array}{c}\text { Vitins \& } \\
\text { Axhausen, } 2018\end{array}$ & & $\begin{array}{c}\text { Method for } \\
\text { extracting } \\
\text { grammars based on } \\
\text { their effectiveness } \\
\text { in network design. }\end{array}$ & & & YES & YES \\
\hline \multirow{3}{*}{ Generative } & $\begin{array}{l}\text { MIT Sustainable } \\
\text { Design Lab }\end{array}$ & $\begin{array}{l}\text { Reinhart, Dogan, } \\
\text { Jakubiec, Rakha } \\
\text { \& Sang, } 2013\end{array}$ & UMI & $\begin{array}{l}\text { Development of a } \\
\text { simulation } \\
\text { environmental } \\
\text { performance and } \\
\text { walkability. }\end{array}$ & Rhinoceros3D & $\begin{array}{l}\text { Python and Visual } \\
\text { Programming - } \\
\text { Grasshopper }\end{array}$ & NO & NO \\
\hline & $\begin{array}{l}\text { MIT Sustainable } \\
\text { Design Lab }\end{array}$ & $\begin{array}{c}\text { Rakha \& Reinhart, } \\
2013\end{array}$ & module for UMI & $\begin{array}{l}\text { Urban mobility } \\
\text { simulation module } \\
\text { for UMI. }\end{array}$ & Rhinoceros3D & $\begin{array}{l}\text { C\# and Visual } \\
\text { Programming - } \\
\text { Grasshopper }\end{array}$ & NO & NO \\
\hline & $\begin{array}{c}\text { Research Center } \\
\text { for Architecture, } \\
\text { Urbanism and } \\
\text { Design (CIAUD)- } \\
\text { University of } \\
\text { Lisbon }\end{array}$ & $\begin{array}{c}\text { De Klerk \& Beirão, } \\
2017\end{array}$ & $\begin{array}{c}\text { CIM-st (module of CIM } \\
\text { - See Beirão, Duarte, } \\
\text { Stouffs \& Bekkering, } \\
2012\end{array}$ & $\begin{array}{l}\text { Development of a } \\
\text { design interface for } \\
\text { semi-automatic } \\
\text { gneration of street } \\
\text { cross sections. }\end{array}$ & Rhinoceros3D & $\begin{array}{l}\text { Visual } \\
\text { Programming - } \\
\text { Grasshopper }\end{array}$ & YES & NO \\
\hline \multirow{4}{*}{ Parametric } & $\begin{array}{l}\text { Delft University } \\
\text { of Technology }\end{array}$ & $\begin{array}{l}\text { Nourian, Sariylidiz } \\
\text { \& Rezvani, } 2013\end{array}$ & Cheetah & $\begin{array}{l}\text { Urban design } \\
\text { support tool for } \\
\text { distributing mixed } \\
\text { land-uses based on } \\
\text { spatial analysis, } \\
\text { geographic location } \\
\text { and density. }\end{array}$ & Rhinoceros3D & $\begin{array}{l}\text { VB.Net and Visual } \\
\text { Programming - } \\
\text { Grasshopper }\end{array}$ & NO & NO \\
\hline & $\begin{array}{l}\text { PROURB - } \\
\text { Federal } \\
\text { University of Rio } \\
\text { de Janeiro }\end{array}$ & $\begin{array}{l}\text { Lima, } \\
\text { Montenegro, } \\
\text { Paraizo \& Kós, } \\
2017\end{array}$ & UrbanMetrics & $\begin{array}{l}\text { Development of } \\
\text { computational } \\
\text { methodology to } \\
\text { support and } \\
\text { optimize urban } \\
\text { planning decisions } \\
\text { through the use of } \\
\text { indexes to measure } \\
\text { walkability, } \\
\text { accessibility, } \\
\text { density and } \\
\text { diversity. }\end{array}$ & Rhinoceros3D & $\begin{array}{l}\text { Visual } \\
\text { Programming - } \\
\text { Grasshopper }\end{array}$ & NO & NO \\
\hline & City Form Lab & $\begin{array}{l}\text { Sevtsuk \& Kalvo, } \\
2016\end{array}$ & UNA Toolbox & $\begin{array}{c}\text { Tool for trip } \\
\text { generation and } \\
\text { network analysis. }\end{array}$ & $\begin{array}{c}\text { ArcGIS or } \\
\text { Rhinoceros3D }\end{array}$ & & NO & NO \\
\hline & $\begin{array}{l}\text { Bauhaus- } \\
\text { University } \\
\text { Weimar }\end{array}$ & $\begin{array}{l}\text { Schneider, Bielik } \\
\text { and König, } 2012\end{array}$ & $\begin{array}{l}\text { DeCodingSpaces } \\
\text { Toolbox }\end{array}$ & $\begin{array}{l}\text { Development of } \\
\text { graph based } \\
\text { components for } \\
\text { integrating network } \\
\text { analysis in } \\
\text { Grasshopper for } \\
\text { Rhinoceros3D. }\end{array}$ & Rhinoceros3D & C\# & NO & NO \\
\hline
\end{tabular}

Aschwanden et al. (2011) combined CityEngine, a procedural urban modeling platform, with a commercial agent-based crowd simulation tool called Massive Software to visualize interactions between the built environment and travel behavior. The workflow developed by the authors uses input from a simplified model of streets and buildings to generate control data for agents representing pedestrian and vehicle movement. The tools were used to simulate and evaluate scenarios for the compact development of a suburban town. The agentbased simulation was divided into two parts, one using pedestrians and a second with vehicles, to evaluate the interactions of the agents with the built environment. They believe their tool could be used for planning, allowing for greater interaction between stakeholders.

Koltsova, Kunze and Schmitt (2012) created a method for translating urban qualities into parameters that can be applied to generate urban spaces that promote walkability. Through a literature review, they produced a list of desirable qualities for urban space and design parameters to achieve them. These qualities were then translated into parametric components using Grasshopper for Rhinoceros as tools for design and evaluation. The tools were applied to projects in an architecture and urbanism undergraduate course for validation. CityEngine was used for visualizing results.

Garcia-Dorado, Aliaga and Ukkusuri (2014) developed a procedural urban modelling environment for network redesign that allows users to interactively input a desired traffic behavior to automatically generate possible urban solutions that can lead to that outcome. Their procedural model is inspired by methods used to develop CityEngine but focusing on road geometry. Data for modeling job distribution and people was extracted from a Geographic 
Information System (GIS). The generically generated urban model can be manipulated by a user through paintbrushes to define zones where they wish to increase, decrease of maintain traffic. The model adapts to the required behavior by adding or deleting roads from the network in the most cost-effective combination. Lanes can be added or change directions. People can be relocated to reduce traffic and redirected to a lower traffic zone. Job distribution can be altered. Traffic is simulated over discrete time steps. For urban planning, this tool can be an interesting way to generate possible scenarios for traffic that can be used for informing large or medium scale projects that may close off roads for vehicles and change street directions and width. However, it does not support smaller scale design decisions. This tool was developed to extend UrbanSim.

Vitins and Axhausen (2016) present an extensive survey on the use of grammars for urban and transport networks. It is used to create a standardized method to extract grammars according to an assessment of their effectiveness. This study was further developed in Vitins and Axhausen (2018). They consider grammars a powerful method for retaining knowledge from diverse disciplines like transport planning and architecture to generate informed planning decisions. However, since grammars are mainly based on rules of thumb, they lack proper validation. To solve this problem, they apply their method to the case of network topologies and intersections. Different types of intersections are compared in terms of the network topology and the travel flows they generate through the use of elasticity measures. The conclusion is that each travel mode needs different network densities and intersection types. While motorized vehicles function better with lower intersection density and four-way intersections, this is not the case with pedestrian which require denser network topologies, and benefit from a higher density of three-way intersections.

Reinhartet al. (2013) present the development of an "urban modeling design platform" (p.477), called UMI, to enable the simulation and environmental performance analysis of the built environment on a neighborhood scale. It integrates existing energy performance plugins for Rhino3D, Grasshopper for visual scripting and components developed by the group for walkability assessment. The mobility module in UMI, is further explained in Rakha and Reinhart (2013). It uses a fourstep transportation model to estimate trips. They suggest that trip generation, which in general uses empirical data by location, can be estimated through GPS data in mobile phones. However, in the article, they use their own estimates with a walkability calculator, which was scripted in $\mathrm{C \#}$, and add-on for Rhino3D to calculate the shortest paths. In addition, they use temperature and rainfall data to determine probable mode choices. This information is used to calculate carbon emissions. The mobility module in UMI described by Rakha and Reinhart (2013) is a relevant approach that integrates traffic modeling into Grasshopper. Unfortunately, it is not available for testing.

De Klerk and Beirão (2017) developed a parametric model for the automatic generation of street cross sections based on a set ontology. The tool has a visual output which allows users to compare and choose between generated sections and is integrated with their City Information Modelling Tool. The ontology is based on shape grammars (Stiny \& Gips, 1972) which allows recombination, generating a variety of possible outcomes. The ontology makes it possible for the system to evaluate design outcomes and ask the user to correct mistakes, such as designing a street that is wider than is possible in its location. The system has two evaluation outputs displayed as pie charts. The first informs the width of the street that is occupied by each type of component and the second displays the tree coverage for the sidewalks in the design. This allows designer to visualize the impact of design decision to a certain extent. However, the tool does not integrate the design to the rest of the transportation network and is only marginally concerned with design impact on travel behavior. The evaluation of pedestrian-friendly aspects of the design is limited to a greater participation of sidewalks and bicycle lanes in the overall width of the street.

The paper by De Klerk and Beirão (2017) is the most recent and relevant to this survey out of the five articles from the research conducted by Beirão on City Information Modeling (CIM) that appeared in this SML survey. However, the earlier publications have interesting information on how the CIM platform was development. The research project City Induction (Beirão et al., 2012; Duarte et al., 2012) involved several researchers in the development of a computational platform to generate possible scenarios as a tool for the urban design process at the scale of the site. The research applied three different theories to the development of the parametric model: (1) pattern language (Alexander, 1977), for the formulation of urban programs, based on an analysis of the context; (2) descriptive grammars (Stiny \& Gips, 1972) for generating urban plans consistent with the formulated program; and (3) space syntax (Hillier \& Hanson, 1984) for the evaluation of the generated urban plans. These three partial models were unified through ontologies that described concepts of the urban environment and the process of urban development. The modeling environment imports spatial data from a GIS. The research developed by Beirão et al. (2010) was one of the results of this project. It applied standard solutions and rules of thumb, broadly accepted in the field of urbanism and described in academic and professional literature, to develop a generative system based on shape grammars. This resulted in urban induction patterns that can be used to reproduce a design concept in different urban contexts. A set of urban induction patterns, chosen by a designer for a project, becomes an urban grammar.

Nourian, Sariylidiz and Rezvani (2013) developed a parametric tool for the distribution of mixed land uses in the city. The method is based on the concept of gravitational models, where the attraction of locations of interest decays with the distance. In this case, the authors use locations in the street network as the attractors. Based on space syntax but using graph theory to develop a method for network analysis, they use accessibility values to derive weights that can be assigned to attractors for each type of land use. It assumes that each type of land use has a different set of attractors. Initial inputs are the optimal percentage distribution of land uses and weights for the attractors. The algorithm then automatically assigns a combination to each block based on its distance to the attractors while obeying the overall distribution in the total area. The authors demonstrate how the same method can be applied to density distribution. This idea is further explored by Nourian and Sariyildiz (2012) who propose a computational design method for distributing density in an existent urban 
configuration according to "walkability gradients" (p.1). According to the authors, locations that have more provisions to support walkability, e.g. better service and commerce availability, access to transit, street connectivity and flatter topography, should have the highest densities. The walkability gradient is calculated as the easiest walkable paths between two points of attraction, based on an algorithm that finds the shortest and flattest routes in a street configuration. Each block of a configuration is scored according to its walkability gradient producing an axial map. The methods described in these articles were further developed into a tool for analyzing, synthesizing and evaluating urban design from its spatial configuration, namely, how spaces are connected to each other, which affects traffic patterns and accessibility. They use graph theory to numerically model spatial configurations and analyze the impacts of urban design on the accessibility for pedestrians and cyclists. This model generated an analytical method for urban networks. It considers cognitive and physical aspects, for pedestrians and cyclists, to finds the shortest, simplest and less physically exerting routes between points of interest in a city, by comparing dimensions such as flatness, distance and travel time. The method was used to make a plug-in for Grasshopper, called Cheetah (Nourian et al., 2015)

Lima et al. (2017) combined metrics, indexes and principles from Transit Oriented Development (TOD) to develop a computational methodology to support urban planning decisions through the use of parametric tools. It applies different indexes to measure walkability, accessibility, density and diversity. Space syntax (Hillier \& Hanson, 1984) is used to measure network connectivity and fitness functions in order to analyze and optimize the performance of urban mobility and land use configurations. The analytical and optimization modules are based on six different algorithms. The first calculates physical proximity between origins and destinations (points of interest) in the urban network, taking topography into account, and scores the locations according to their proximity. The second is a topological proximity algorithm based on space syntax that calculates the shortest path between origins and destinations. The third, measures the variety of amenities by calculating an index which relates the average distance between a given location and all the amenities within walking distance. This allows to differentiate between locations close to a single amenity, and those with greater varieties of urban services. The fourth measures the recurrence of amenities by considering the ratio between the number of amenities and the number of plots within a 20-minute walk. The fifth measures the diversity of land-uses, which is the proportion of non-residential and residential areas in relation to the total area. The ideal proportion is $50 / 50$. Lastly, there is a density calculator. The authors used Grasshopper evolutionary algorithm add-ons to enhance the optimization capabilities of the model.

The UNA Toolbox incorporates street network analysis in Rhino3D. It uses a combination of approaches similar to those described by Nourian and Sariyldiz (2012) and Rhaka and Reinhart (2013). UNA was originally created as a plugin for ArcGIS (esri.com) in 2011 and in 2015 was adapted to Rhino3D to integrate network analytics into the design process and allow for interactive design alteration (Sevtsuk \& Kalvo, 2016). Differently from space syntax methods, it uses centerlines. The inputs for generating a network analysis using UNA are the spatial network and the origin and destination points. These points can be weighted to reflect the number of occupants. The toolbox calculates five different indexes: "Reach, Gravity Index, Betweenness, Closeness, and Straightness" (Sevtsuk \& Mekonnen, 2012, p.292). Reach describes the number of nodes that can be reached from a central node, within a predefined distance calculated at a shortest path, and outputs the number of reachable locations. Gravity index measures travel behavior through a gravity-based model, using points to represent origins and destinations. The attraction of a destination decays with its distance from an origin. Individual buildings can be given weights, thus attracting a higher share of the generated trips. Betweenness measures the number of times a certain building is passed by the shortest path between an origin and a destination, meaning the potential traffic for a point in the network. Closeness measures how close a point is in relations to other points in the network within a certain distance. Straightness measures the difference between the shortest walk distance and the straight line connecting two points in the network. This can be used to generate a map of the places that are located in the more direct routes. Different travel modes can be modeled in UNA by adjusting the travel ranges and scales of the analysis.

Schneider, Bielik and König (2012) present graph-based components for integrating network analysis into Grasshopper to allow for changes in the network to be automatically analyzed eliminating the need to export the redefined network to a second software, improving the workflow. Dennemark et al. (2017) discuss further developments in this research for the automatic generation of urban networks and land-use patterns considering walkability and urban densification. The components developed in the former research were used in a design studio to study different planning strategies that could be developed with the use of the tools. These components are also available for download as a network analysis toolbox called DeCodingSpaces.

\section{DISCUSSION}

Across the papers surveyed, the use of grammars for extracting rules for urban components and network generation is a recurrent approach. Some papers do not cite shape grammars, but are based on tools that do, such as Garcia-Dorado, Aliaga \& Ukkusuri (2014). Beirão et al. (2012) use shape grammars to generate urban networks, which are further developed by De Klerk and Beirão (2017) to generate components for street profiles. Across the procedural models surveyed, grammars were studied and developed to generate networks and buildings and to simulate urban growth (Weber Et Al., 2009; Aschwanden Et Al.,2011; Koltsova, Kunze \& Schmitt, 2012; Garcia-Dorado, Aliaga \& Ukkusuri, 2013). Vitins \& Axhausen $(2016,2018)$ show the development of a method for extracting and evaluating grammars by comparing their performance through traffic modeling.

Pattern Language (Alexander, 1977) is also cited across studies. According to Vitins \& Axhausen (2016, p. 72-73) the approach provided by this seminal work is "inductive" because it is mostly concerned with the description of the relations between elements of the urban environment, which allow patterns to emerge. Shape grammars are often used in "analytical" approaches because of their focus on geometric rules. 
A number of relevant parametric, generative and procedural approaches that address the relation between the built environment and travel behavior were found in the survey. Some of the tools developed by these studies are open source and can be downloaded and tested. UMI and UNA use algorithms that calculate the shortest path without accounting for the decrease in walkability caused by steep topographies. This question was addressed by Nourian and Sariyldiz (2012) through a model that can be useful particularly when developing cycling paths. Furthermore, Rhaka and Reinhart (2013) follow the hypothesis that if a certain area scores highly in walkability people will choose to walk whenever possible. This assumption is not supported by transport research, which considers that modal choice is the result of synergies between different characteristics of the built environment (Ewing \& Cervero, 2017).

Network analysis using graph theory combined with traffic modelling and walkability indexes are the most used methods for evaluating travel behavior in relation to the built environment. Joining this type of analysis with elasticities can provide an interesting tool for parametric urban design, that is independent from absolute quantification of travel demand (Vitins \& Axhausen, 2018). Elasticities are mainly available for developed countries, where empirical research relating travel behavior and the built environment is more numerous. Different urban contexts can generate different elasticity measures (Ewing \& Cervero, 2017). Therefore, to use these measures in a parametric tool, focusing on urban design, elasticities should be incorporated as a set of parameters that can be modified by the user. As more empiric research becomes available, more precise elasticity values may also be developed, including those for different urban contexts, e.g. for developing countries, which would allow the improvement of the model's precision.

\section{CONCLUSION}

Through the survey presented in this paper it can be concluded that there have been a number of efforts to bridge the gap between theories from the field of transportation and tools to support urban design practice. However, retrofitting streets is seldom their focus. The models developed in the reviewed papers tend to focus either on active modes or vehicular flow. Further studies are still needed to connect urban design practice with modal share assessments.

The support methods currently available for street design are guides and toolkits grounded on philosophies such as New Urbanism, Transport Oriented Design and Smart Growth. These approaches convey geometric rules, urban policies, design patterns, standards for urban equipment, lighting and materials. This type of design data is mostly presented in the form of tables that relate each mode of transportation to street dimensions and the advantages of each design approach. However, analyzing all of these recommendations and combining them in a project is a highly complex task with numerous possible, and potentially conflicting, responses.

Parametric, generative and procedural modeling can be used to improve the application of these rules for street design. Allowing designers to visualize the impacts of their design decisions on travel behavior can help to minimize arbitrary decision-making in city planning.
The simulation of future scenarios can aid designers to grapple with urban mobility and encourage the development of more innovative design solutions for a future without the prevalence of the car. This is relevant to the improvement of urban quality and to making densification viable even in cities that still do not have an efficient urban mobility system. It is needless to say that investments in public and/or alternative forms of transportation is mandatory if we want to reduce the use of the private car, and that urban design cannot perform a miracle if this premise is not attained.

The next step in this research is to use this theoretical background to develop a framework for the generation of possible three-dimensional scenarios for retrofitting the design of urban streets while visualizing the impact of design decisions on modal share.

This approach will use the rules extracted from guides and toolkits for urban street design to develop parametric components for urban design. Existing tools such as the UNA Toolbox and the DeCodingSpaces Toolbox will be tested to incorporate spatial analysis functions in the workflow and an evaluation module will be developed using elasticity measures (Ewing \& Cervero, 2017).

\section{ACKNOWLEDGMENTS}

This study was financed in part by the Coordenação de Aperfeiçoamento de Pessoal de Nível Superior - Brasil (CAPES) - Finance Code 001 through PhD Scholarships in Brazil and abroad (Process 88881.187989/2018-01).

\section{REFERENCES}

Alexander, C., Ishikawa, S., \& Silverstein, M. (1977). A pattern language: towns, buildings, construction. New York: Oxford University Press.

Aschwanden, G. D. P. A., Haegler, S., Bosché, F., Van Gool, L., \& Schmitt, G. (2011). Empiric design evaluation in urban planning. Automation in Construction, 20(3), 299-310. doi:10.1016/j.autcon.2010.10.007

Beirão, J., Duarte, J., Stouffs, R., \& Bekkering, H. (2012). Designing with urban induction patterns: a methodological approach. Environment and Planning B: Planning and Design, 39(4), 665-682. doi:10.1068/b38052

Beirão, J., Mendes, G., Duarte, J., \& Stouffs, R. (2010). Implementing a Generative Urban Design Model. 28th eCAADe Conference, 265-274.

Carlow, V. M. (2016). Limits: Space as resource. Jovis Verlag.

Cuthbert, A. R. (2007). Urban design: requiem for an era- review and critique of the last 50 years, URBAN DESIGN International12, 177-223. doi: 10.1057/palgrave.udi.9000200

De Klerk, R., \& Beirão, J. N. (2017). CIM-St. CAAD Futures, 4259. doi: 10.1007/978-981-10-5197-5_3

Dennemark, M., Schneider, S., Koenig, R., Abdulmawla, A., \& Donath, D. (2017). Towards a modular design strategy for urban masterplanning. 35th eCAADe Conference, 485-494.

Dovey, K., \& Pafka, E. (2016). The science of urban design? URBAN DESIGN International, 21(1), 1-10. doi: 10.1057/udi.2015.28

Duarte, J. P., Beirão, J. N., Montenegro, N., \& Gil, J. (2012). City Induction: A Model for Formulating, Generating, and Evaluating Urban Designs In: Arisona S.M.et al.(eds) Digital Urban Modeling and Simulation. Communications in Computer and Information Science, 242. Springer, Berlin, Heidelberg. doi: 10.1007/978-3-642-29758-8_5 
Ewing, R., \& Cervero, R. (2010). Travel and the Built Environment. Journal of the American Planning Association, 76(3), 265-294. doi: 10.1080/01944361003766766

Ewing, R., \& Cervero, R. (2017). "Does Compact Development Make People Drive Less?" The Answer Is Yes. Journal of the American Planning Association, 83(1), 19-25. doi:10.1080/01944363.2016.1245112

Ewing, R., Tian, G., \& Lyons, T. (2018). Does compact development increase or reduce traffic congestion? Cities, 72, 94-101. doi: 10.1016/j.cities.2017.08.010

Farr, D. (2013). Urbanismo Sustentável: desenho urbano com a natureza. Porto Alegre: Bookman.

Foroughmand Araabi, H. (2017). Multiple expectations: assessing the assumed roles of theory in relation to urban design. Journal of Urban Design, 22(5), 658-669. doi: 10.1080/13574809.2017.1298402

Garcia-Dorado, I., G. Aliaga, D., \& V. Ukkusuri, S. (2014). Designing large-scale interactive traffic animations for urban modeling. Computer Graphics Forum, 33(2), 411-420. doi: $10.1111 /$ cgf.12329

Gunder, M. (2011). Commentary: Is Urban Design Still Urban Planning? An Exploration and Response. Journal of Planning Education and Research, 31(2), 184-195. doi: 10.1177/0739456X10393358

Handy, S. (2017). Thoughts on the Meaning of Mark Stevens's Meta-Analysis. Journal of the American Planning Association, 83(1), 26-28. doi: 10.1080/01944363.2016.1246379

Hillier, B., \& Hanson, J. (1984). The social logic of space, 1984. Cambridge: Cambridge University Press.

Jacobs, J. (1961). The death and life of great American cities. Vintage. New York, New York, USA.

Koltsova, A., Kunze, A., \& Schmitt, G. (2012). Design of Urban Space at Pedestrian Scale: A Method for Parameterization of Urban Qualities. In 2012 16th International Conference on Information Visualisation, 403-409. doi: 10.1109/IV.2012.73

Lehmann, S. (2016). Sustainable urbanism: towards a framework for quality and optimal density? Future Cities and Environment, 2(8). Doi: 10.1186/s40984-016-0021-3

Lima, F., Montenegro, N., Paraizo, R., \& Kós, J. (2017). Urbanmetrics: An algorithmic-(Para)metric methodology for analysis and optimization of urban configurations. CUPUM 2017. Lecture Notes in Geoinformation and Cartography. Springer, Cham. doi: doi.org/10.1007/978-3-319-57819-4_3

Marshall, S. (2009). Cities, design and evolution. Routledge.

Marshall, S. (2012). Science, pseudo-science and urban design. URBAN DESIGN International, 17(4), 257-271. doi: 10.1057/udi.2012.22
Nourian, P., Rezvani, S., Sariyildiz, S. \& Hoeven, F.(2015). Configurbanist-Urban Configuration Analysis for Walking and Cycling via Easiest Paths. 33rd eCAADe Conference, 553564.

Nourian, P., \& Sariyildiz, S. (2012). Designing for pedestrians. In New Urban Configurations (pp. 659-665). IOS Press. doi:10.3233/978-1-61499-365-0-665

Nourian, P., Sariylidiz, S., \& Rezvani, S. (2013). An interactive computational methodology for urban mixed-use allocation according to density distribution, network analysis and geographic attractions. International Conference on Changing Cities,1360-1368.

Rakha, T., \& Reinhart, C. F. (2013). A Carbon Impact SimulationBased Framework For Land Use Planning And NonMotorized Travel Behaviour Interactions. In 13th Conference of International Building Performance Simulation Association.

Reinhart, C. F., Dogan, T., Jakubiec, J. A., Rakha, T., \& Sang, A. (2013). UMI - An urban simulation environment for building energy use, daylighting and walkability. 13th Conference of International Building Performance Simulation Association.

Schneider, S., Bielik, M., \& König, R. (2012). The parametric exploration of spatial properties: coupling parametric geometry modeling and the graph-based spatial analysis of urban street networks. 2012 Symposium on Simulation for Architecture and Urban Design.

Sevtsuk, A., \& Kalvo, R. (2016). Urban Network Analysis toolbox for Rhinoceros 3D. American Planning Association Technology Today Newsletter, 112, 4-5.

Sevtsuk, A., \& Mekonnen, M. (2012). Urban Network Analysis Toolbox. International Journal of Geomatics and Spatial Analysis, 22(2), 287-305.

Stevens, M. R. (2017). Does Compact Development Make People Drive Less? Journal of the American Planning Association, 83(1), $\quad 7-18$ doi: 10.1080/01944363.2016.1240044

Stiny, G., \& Gips, J. (1972). Shape Grammars and the Generative Specification of Painting and Sculpture," Information Processing 71, IFIP, North-Holland, Amsterdam.

Vitins, B. J., \& Axhausen, K. W. (2016). Shape grammars overview and assessment for transport and urban design: Review, terminology, assessment, and application. Journal of Transport and Land Use, 9(1). doi: 10.5198/jtlu.2016.620

Vitins, B. J., \& Axhausen, K. W. (2018). Extraction and evaluation of transportation network grammars for efficient planning applications. Design Science, 4(2). doi: 10.1017/dsj.2017.29

Weber, B., Müller, P., Wonka, P., \& Gross, M. (2009). Interactive Geometric Simulation of 4D Cities. Computer Graphics Forum, 28(2), 481-492. doi: 10.1111/j.14678659.2009.01387.x 